\title{
Características de plantas de girassol, em função da época de semeadura, na Região Noroeste do Rio Grande do Sul
}

\author{
Characteristics of sunflower in function of sowing dates in northwest region of \\ Rio Grande do Sul, Brazil
}

\author{
Antonio Mauro Rodrigues Cadorin' ${ }^{\text {I }}$ Velci Queiróz de Souza ${ }^{\text {II }}$ Paulo Augusto Manfron ${ }^{\text {II }}$ \\ Braulio Otomar Caron" Sandro Luís Petter Medeiros ${ }^{\text {III }}$
}

\section{RESUMO}

Em virtude da importância da cultura do girassol (Helianthus annuus L) no Brasil, o objetivo deste trabalho foi avaliar a interferência das épocas de semeadura sobre caracteres morfológicos (altura de planta e tamanho de capítulo) e de produção da cultura (rendimento e massa de mil aquênios). Os genótipos cultivados foram Hélio 250, 251, 358, 884 e 885 na safra 2008-09 em três épocas de semeadura (27/agosto, 14/outubro e 13/dezembro) e Hélio 250, 251, 253; 360, HLA 211 e Paraíso 33 na safra 2009-10 em três épocas de semeadura (31/agosto, 12/novembro e 09/dezembro). $O$ experimento foi conduzido em blocos ao acaso, em quatro repetições, em Frederico Westphalen, na região Noroeste do Rio Grande do Sul. Análises de variância individuais e conjunta foram realizadas, sendo que, para a comparação das médias das estimativas, aplicou-se o teste de Tukey em nível de $5 \%$ de probabilidade. Para as constituições genéticas, não houve diferenças significativas em rendimento de aquênios. Somente para a estatura da planta há influência do ambiente e das épocas de semeadura, sendo que, para o tamanho do capítulo, ocorre influência do ambiente e, para o rendimento de aquênios, verifica-se que há incrementos próximos de $600 \mathrm{~kg} \mathrm{ha}^{-1}$ quando as plantas são submetidas às condições ambientais e à época de semeadura favoráveis, enquanto ocorre diminuição da massa de mil aquênios com o avanço da época de semeadura.

Palavras-chave: biodiesel, Helianthus annuus L., interação genótipo $x$ ambiente.

\section{ABSTRACT}

Based on the importance of production of sunflower (Helianthus annuus L.) in Brazil the aim of this study was to evaluate the influence of the environment of cultivation and

\begin{abstract}
sowing date on morphological (plant height and chapter size) and crop production (grain yield and one thousand achene weight) characteristics of sunflower. The genotypes used in this stduty were Hélio 250, 251, 358, 884 and 885 during the 2008-09 growing season and the Hélio 250, 251, 253, 360, HLA211 and Paraíso 33 in the 2009-10 growing season, cultivated in three sowing dates (august, october and december). The experiment was conducted in randomized block design with four replications in Frederico Westphalen in Northwestern of the Rio Grande do Sul, Brazil. Analyses were individual fitness and joint variance, whereas for the comparison of averages of the estimates was applied the Tukey test at 5\% level of probability. The genetic constitutions do not revealed differences in grain yield, only the plant height is influenced by the environment and sowing dates. The capitulum size is influenced by environment and achene yield responds positively in favorable environmental conditions and sowing date, with increments near $600 \mathrm{~kg} \mathrm{ha}^{-1}$, while reducing the one thousand achene weight with advancing sowing date.
\end{abstract}

Key words: biodiesel, environment and genotypes interaction, Helianthus annuus $L$.

\section{INTRODUÇÃO}

A produção de girassol (Helianthus annuus L.) no Brasil tem se expandido nos últimos anos nas regiões Centro-Oeste, Sudeste e principalmente Sul, sendo que a área cultivada no país aumentou de 50,10mil hectares na safra 2004/2005 para 111,30mil hectares em 2007/2008, na qual a região Sul foi

Instituto Federal de Mato Grosso (IFMG), Campus São Vicente, 78106-960, Santo Antonio do Leverger, MT, Brasil. E-mail: amrcadorin@gmail.com. Autor para correspondência.

IIDepartamento de Ciências Agronômicas e Ambientais, Centro de Educação Superior Norte-RS (CESNORS), Universidade Federal de Santa Maria (UFSM), Santa Maria, RS, Brasil.

IIIDepartamento de Fitotecnia, Centro de Ciências Rurais (CCR), UFSM, Santa Maria, RS, Brasil. 
responsável por mais de $17 \%$ de toda a área ocupada com esta oleaginosa no território brasileiro (CONAB, 2010); por outro lado, os índices de produtividade média $\left(1.323 \mathrm{~kg} \mathrm{ha}^{-1}\right)$ não sofreram ganhos consideráveis nos últimos anos.

O cultivo de girassol atendia, até bem pouco tempo, basicamente a três objetivos: produção de aquênios para alimentação de pássaros; produção de óleo comestível e arraçoamento animal. Entretanto, especialmente a partir de 2005, a cultura tem despertado o interesse de agricultores, técnicos e empresas, devido à possibilidade de utilização do óleo derivado das sementes desta espécie na fabricação de biodiesel (BACKES et al., 2008).

A pesquisa tem sido decisiva para dar suporte tecnológico ao desenvolvimento da cultura, garantindo melhores produtividades e retornos econômicos competitivos, pois, entre as várias tecnologias desenvolvidas para a produção do girassol, a escolha adequada de cultivares constitui um dos principais componentes do sistema de produção da cultura (PORTO et al., 2007).

A alta eficiência em utilizar a água disponível no solo para o seu desenvolvimento, a capacidade de produzir grande quantidade de matéria seca em condição de estresse hídrico (SHEAFFER et al., 1977) e a tolerância à ampla faixa de temperaturas, sem redução significativa da produção (CASTRO et al., 1997), são fatores que estimulam o cultivo do girassol para a produção de grãos, como uma cultura alternativa e que agrega renda.

Apesar de o girassol ter facilidade de adaptação em vários tipos de solo, o ideal é a utilização de solos corrigidos, com pH entre 5,2 e 6,4, a fim de se evitar sintomas de toxidez; além disso, solos profundos, de textura média, férteis, planos e bem drenados favorecem o bom desenvolvimento do sistema radicular. Essas características dão maior resistência à seca e ao tombamento, proporcionando maior absorção de água e nutrientes e, consequentemente, maior rendimento (SILVA\& MUNDSTOCK, 1990).

As características da planta de girassol podem ser alteradas dependendo da época de semeadura, como a estatura, o tamanho do capítulo, as quais, segundo CASTIGLIONI et al. (1994), variam de acordo com o genótipo e as condições edafoclimáticas, além da época de semeadura (MELLO et al., 2006).

Diante disso, o objetivo deste trabalho foi avaliar a influência de épocas de semeadura sobre caracteres morfológicos (altura de planta e tamanho de capítulo) e de produção de grãos (rendimento e massa de mil aquênios) da cultura do girassol em dois anos de cultivo.

\section{MATERIAL E MÉTODOS}

Localização do experimento

O experimento foi conduzido nos anos agrícolas de 2008/09 e 2009/10 nas épocas de cultivo dos meses de agosto, setembro e outubro de cada ano agrícola no campus da UFSM de Frederico Westphalen - RS, situado na BR 386, linha Sete de Setembro, latitude 27²3'26"; longitude 5325' 43" e a 641,3m de altitude.

Segundo a classificação climática de Köppen, o clima da região é $\mathrm{Cfb}$, ou seja, subtropical úmido com temperatura média anual de $19,1^{\circ} \mathrm{C}$, variando com máxima de 38 e mínima de $0^{\circ} \mathrm{C}$. Os dados meteorológicos necessários aos modelos foram coletados na Estação do Instituto Nacional de Meteorologia (A 854), situada no campus da UFSMCESNORS. A tecnologia de produção adotada na cultura seguiu as indicações para o cultivo de girassol no Estado do Rio Grande do Sul propostas por LEITE et al. (2007).

\section{Material experimental}

No ano agrícola de 2008/09, utilizaram-se cinco genótipos comerciais de girassol nas três épocas de cultivo, sendo detentora dessas sementes a empresa HELIANTHUS DO BRASIL ${ }^{\circledR}$. Considerando que, para as análises conjuntas envolvendo as duas safras, foram cultivados somente os dois materiais Hélio 250 e Hélio 251 , os quais foram repetidos e testados. Os materiais utilizados para este ano agrícola foram: HÉLIO 250, HÉLIO 251, HÉLIO 358, HÉLIO 884, HÉLIO 885.

No ano agrícola de 2009/10, utilizaram-se seis genótipos comerciais de girassol nas três épocas de cultivo, sendo detentora dessas sementes as empresas HELIANTHUS DO BRASIL ${ }^{\circledR} \mathrm{e} \mathrm{NIDERA}^{\circledR}$. Os materiais utilizados para este ano agrícola foram: HÉLIO 250, HÉLIO 251, HÉLIO 253, HÉLIO 360, HLA 211, PARAISO $33\left(\right.$ NIDERA $\left.^{\circledR}\right)$.

\section{Delineamento experimental}

Os materiais foram distribuídos na área experimental, utilizando o delineamento de blocos completos casualizados, em quatro repetições; o espaçamento utilizado foi de $0,80 \mathrm{~m}$ entre linhas e $0,25 \mathrm{~m}$ entre plantas, totalizando uma área de $19,20 \mathrm{~m}^{2}$, composta por 96 plantas, das quais 48 compuseram a parcela útil.

\section{Caracteres avaliados}

a) Altura da planta ou do capítulo (AP): obtida medindose dez plantas em centímetros da área útil da parcela selecionadas aleatoriamente, desde o nível do solo até a inserção do capítulo, com uma régua de madeira graduada, no período de floração plena.

Ciência Rural, v.42, n.10, out, 2012. 
b) Diâmetro ou tamanho do capítulo (TC): obtido medindo-se o diâmetro do receptáculo em centímetros da inflorescência de dez plantas da área útil da parcela selecionadas aleatoriamente, com uma régua graduada, no período de maturação fisiológica.

c) Massa de mil aquênios (MMA): obtida pela amostragem aleatória de 100 aquênios de cada parcela e posterior pesagem deles em balança de precisão, expressa em gramas, após extrapolado para a massa de 1000 aquênios baseado na metodologia proposta por LOPES et al. (2009).

d) Rendimento de aquênios (REND): em $\mathrm{kg} \mathrm{ha}^{-1}$ obtido através do cálculo proporcional do rendimento de aquênios por parcela extrapolada para uma área de um hectare, corrigindo-se a umidade para $11 \%$.

\section{Análise estatística}

Após as avaliações e tabulações dos dados em planilha eletrônica, foram submetidos à análise de variação pelo Procedimento GLM (General Linear Models) do pacote estatístico SAS Learning Edition (2002), com a finalidade de corrigir os efeitos das parcelas perdidas durante a condução do experimento. Após a verificação da significância das interações, elas foram desmembradas em seus efeitos simples e as médias foram comparadas pelo modelo descrito por Tukey, a 5\% de probabilidade.

\section{RESULTADOS E DISCUSSÃO}

Para as análises individuais de cada ano de cultivo, os coeficientes de variação para todos os caracteres avaliados oscilaram desde 4,35 até 18,42, sendo considerados de baixa a média magnitude, conforme classificação de PIMENTEL-GOMES (1990). Portanto, o planejamento experimental e o delineamento estatístico foram eficientes para eliminar heterogeneidades que por ventura existissem na área experimental. Para a análise conjunta, os coeficientes de variação das variáveis morfológicas tiveram baixa à média variação, na faixa de 7,68 a 15,60, para altura de planta e rendimento, respectivamente.

A análise de variância dos cinco genótipos para o ano agrícola 2008/09 em duas épocas de cultivo demonstrou que a única variável que não teve diferença significativa para nenhum dos fatores de variação, inclusive a interação, foi o rendimento de aquênios. Para o ano agrícola 2009/10, a interação entre épocas de cultivo (semeadura) dos genótipos foi significativa a $5 \%$ de probabilidade de erro $(\mathrm{P}>\mathrm{F})$ para a maioria dos caracteres avaliados, exceto para a variável morfológica tamanho de capítulo. Nos caracteres com interação significativa, os genótipos foram comparados dentro e entre os períodos para cada genótipo.
Na análise de variação conjunta, os dados indicaram que para a interação tripla não houve diferença significativa para nenhum dos caracteres avaliados, sendo que dentre estes, para o tamanho de capítulo, ocorreu diferença somente entre épocas de cultivo. Quanto à altura de planta, houve interação dupla somente entre época e ano, enquanto que as interações duplas entre ano e época e ano e genótipo foram significativas para o rendimento de aquênios.

Os resultados da interação genótipo $\mathrm{x}$ ambiente indicaram que a época de cultivo não causou interferência na expressão do tamanho de capítulo e rendimento de aquênios, sendo que as diferenças entre genótipos são decorrentes do potencial genético de cada material. Segundo PORTO et al. (2007), na cultura do girassol, há variações de comportamento de cultivares em função da região e época de semeadura, em virtude da interação genótipo $\mathrm{x}$ ambiente. Segundo ALLARD (1960), os caracteres que se desenvolvem em curto período de tempo estão menos sujeitos ao efeito de ambiente e teriam maior herdabilidade do que aqueles com maior período de interferência em sua formação, ou seja, quanto menor o período fenológico maior é a herdabilidade e menor a variação frente a diferentes ambientes.

Para a altura de planta no ano agrícola 2008/ 09, na primeira época (Tabela 1), os genótipos Hélio 251 e Hélio 884 tiveram maior estatura, enquanto Hélio 358 e Hélio 250 foram os de menor; na segunda época, os genótipos Hélio 885, Hélio 884 e Hélio 358 foram os de menor porte e o Hélio 251 foi o maior. Quando comparadas as duas épocas de semeadura, nota-se que, para os genótipos Hélio 250 e Hélio 251, não houve diferença entre esses períodos; para o restante dos materiais estudados na segunda época, constatou-se redução na estatura de plantas. Com relação à safra de 2009/10, os genótipos Hélio 360 e HLA 211 foram superiores em altura de plantas somente em relação ao genótipo Hélio 250 na época 1, enquanto na época 20 genótipo HL 211 foi superior somente ao Hélio 250 e 253, não se diferenciando dos demais e, na época 3 , destacou-se com maior porte o genótipo Paraíso 33, o qual foi superior em altura de planta aos demais genótipos, exceto ao HL 211 (Tabela 1).

$\mathrm{Na}$ análise conjunta (Tabela 2), para a altura de planta dentro do ano agrícola 2008/09, os genótipos não diferiram significativamente dentro e entre épocas; no segundo ano, somente para a segunda época houve diferença entre genótipos, sendo o "Hélio 250" aquele com uma menor estatura. Quando comparadas as épocas dentro deste ano, houve redução significativa na altura de plantas da primeira para a segunda e da segunda para a terceira época, respectivamente. Em 
Tabela 1 - Altura de plantas (AP), massa de mil aquênios (MMA), rendimento de aquênios (REND) e tamanho de capítulo (TC) de girassol nas safras de 2008/09 e 2009/10, em três épocas de semeadura. Campus da UFSM - Frederico Westphalen - RS, 2010.

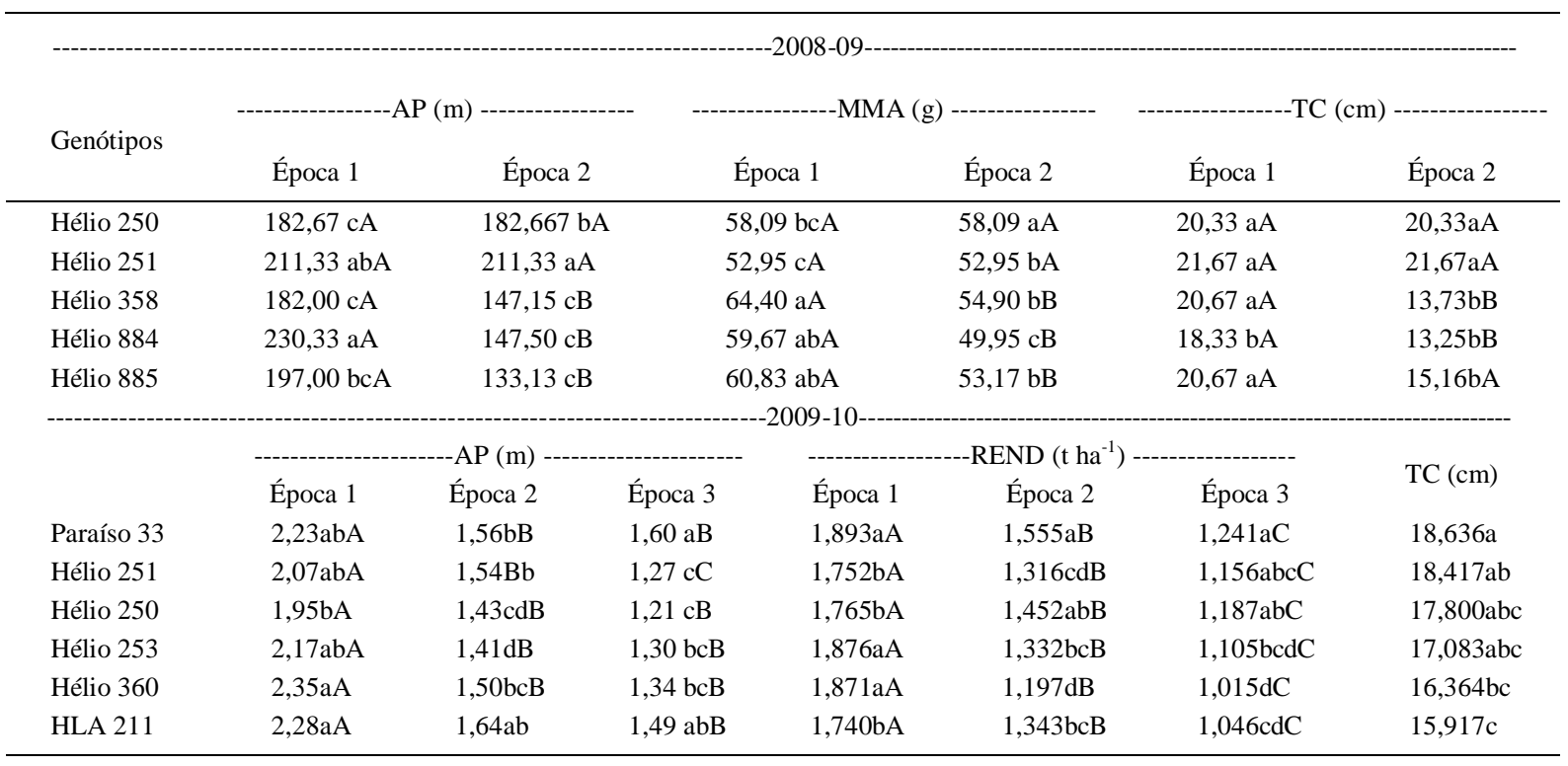

Médias seguidas pelas mesmas letras minúsculas na coluna e maiúsculas na linha não diferem estatisticamente entre si, pelo teste de Tukey em nível de $5 \%$ de significância.

relação aos anos, somente na segunda época, detectouse diferença significativa para o segundo ano em relação ao primeiro.

O diâmetro do capítulo e altura de plantas de girassol em função dos espaçamentos entre linhas não diferiram entre si, obtendo-se em média $11,8 \mathrm{e}$ $92,6 \mathrm{~cm}$, respectivamente, sendo que os valores obtidos para o diâmetro do capítulo podem ser considerados baixos pelo fato de o girassol ter sido cultivado na safrinha, quando ocorreu limitação hídrica em estádios mais avançados de desenvolvimento da cultura (SILVA et al., 2009). A limitação de água no solo proporciona diminuição na altura das plantas de girassol, também restringindo o enchimento de aquênios pelo menor acúmulo de reservas nas folhas/pecíolos, caule e capítulo (CASTRO \& FARIAS, 2005).

Quanto à variável massa de mil aquênios na primeira época de semeadura (Tabela 1), os genótipos Hélio 358, Hélio 884 e Hélio 885 foram aqueles com maiores valores de massa de mil aquênios, tendo o menor valor o genótipo Hélio 251. Entre as épocas de semeadura, os genótipos Hélio 250 e Hélio 251 não diferiram significativamente para a massa de mil aquênios, enquanto, para a segunda época de semeadura, os valores de massa de mil aquênios dos dois genótipos foram superiores aos dos demais. No ano agrícola 2009/10, para a variável rendimento de aquênios (Tabela 1), o genótipo Paraíso 33 foi um dos de melhor resposta em rendimento nas três épocas testadas, porém não se diferenciou na época 1 dos genótipos "Hélio 253" e "Hélio 360"; na época 2 do "Hélio 250", e, além deste, também o genótipo Hélio 251 na época 3.

Pela análise conjunta dos anos agrícolas 2008/09 e 2009/10 (Tabela 2), quando comparados os genótipos quanto ao rendimento dentro do ano agrícola 2008/09, eles não diferiram entre si dentro e também entre as épocas de semeadura. Para o ano 2009/10, somente dentro da segunda época de semeadura o genótipo Hélio 250 foi aquele com maior potencial produtivo, não diferindo para as demais épocas. Quando comparados entre épocas, na terceira, constatou-se produtividade significativamente inferior a primeira e, com relação aos anos, no segundo houve maior produção em relação ao primeiro ano, exceto para "Hélio 251" na segunda época, o qual foi mais produtivo no primeiro ano.

No aspecto de rendimento do girassol, o estudo demonstrou que os genótipos responderam as condições climáticas dos períodos de semeadura testados e também que a variação de rendimento está associada a condições de clima, especialmente observadas no ano agrícola 2008-09, havendo também a influência da época de cultivo demonstrada no ano 2009-10, bem como, na sua condição de clima. 
Tabela 2 - Análise conjunta da altura de planta (AP), tamanho de capítulos (TC) e rendimento de capítulos (REND) de girassol nas safras de 2008/09 e 2009/10, em três épocas de semeadura. Campus da UFSM - Frederico Westphalen - RS, 2010.

\begin{tabular}{|c|c|c|c|c|c|}
\hline \multirow[t]{2}{*}{ Genótipos } & \multicolumn{2}{|c|}{-------------------2008-09--------------------- } & \multirow[b]{2}{*}{ Época 1} & \multirow[b]{2}{*}{ Época 2} & \multirow[b]{2}{*}{ Época 3} \\
\hline & Época 1 & Época 2 & & & \\
\hline H 250 & $182,67 \mathrm{aA} \alpha$ & $182,67 \mathrm{aA} \alpha$ & $195,00 \mathrm{aA} \alpha$ & $143,75 \mathrm{bB} \beta$ & $121,25 \mathrm{aC}$ \\
\hline \multirow[t]{2}{*}{ H 251} & $211,33 \mathrm{aA} \alpha$ & $211,33 \mathrm{aA} \alpha$ & $207,50 \mathrm{aA} \alpha$ & $153,75 \mathrm{aB} \beta$ & $127,5 \mathrm{aC}$ \\
\hline & Época 1 & Época 2 & Época 1 & Época 2 & Época 3 \\
\hline H 250 & $20,33 \mathrm{aA} \alpha$ & $20,33 \mathrm{aA} \alpha$ & $19,00 \mathrm{aA} \alpha$ & $18,50 \mathrm{aA} \alpha$ & $14,75 \mathrm{aB}$ \\
\hline \multirow[t]{2}{*}{ Н 251} & 21,67 aA $\alpha$ & $21,67 \mathrm{aA} \alpha$ & $21,50 \mathrm{aA} \alpha$ & $19,00 \mathrm{aB} \alpha$ & $16,50 \mathrm{aC}$ \\
\hline & Época 1 & Época 2 & Época 1 & Época 2 & Época 3 \\
\hline H 250 & $1167,0 \mathrm{aA} \beta$ & 1167,0 aA $\beta$ & $1765,0 \mathrm{aA} \alpha$ & $1452,5 \mathrm{aAB} \beta$ & $1187,50 \mathrm{aB}$ \\
\hline H 251 & 1540,3 aA $\beta$ & $1540,3 \mathrm{aA} \alpha$ & $1752,5 \mathrm{aA} \alpha$ & $1316,25 \mathrm{bAB} \beta$ & $1156,25 \mathrm{aB}$ \\
\hline
\end{tabular}

Médias seguidas pelas mesmas letras minúsculas na coluna, maiúsculas na linha e grega entre anos não diferem estatisticamente entre si, pelo teste de Tukey em nível de 5\% de significância.

Tais observações são coerentes com UNGARO et al. (2000), BACKES et al. (2008) e PORTO et al. (2007), que também observaram reduções na produção com o retardamento da semeadura de girassol. A produção retrata a importância da época de semeadura para a cultura do girassol, uma vez que pode resultar em redução de até $92 \%$ na produção (AFFÉRRI et al., 2008).

Em março de 2005, os mesmos genótipos utilizados neste experimento foram avaliados por RÊGO FILHO et al. (2006), que obtiveram rendimento médio de grãos de $0,74 \mathrm{t} \mathrm{ha}^{-1} \mathrm{e}$, embora a produção dos genótipos tenha variado entre 0,41 e 1,01 tha $^{-1}$, suas médias foram consideradas estatisticamente iguais. Para o experimento em questão, o híbrido Hélio 251 foi o mais produtivo e os demais foram estatisticamente equivalentes.

O tamanho de capítulo no ano agrícola de 2008/09 (Tabela 1) de todos os genótipos teve resposta similar, exceto o genótipo Hélio 884 que diferiu dos demais, pois se constatou o menor valor de diâmetro na primeira época de semeadura. Os genótipos Hélio 250 e Hélio 251 destacaram-se dos demais na segunda época, além de não terem diferido entre as épocas testadas. Por outro lado, houve redução significativa de diâmetro nos capítulos dos genótipos Hélio 358 e Hélio 884 na segunda época estudada. No agrícola 2009/10, a interação entre épocas e genótipos não foi significativa para a variável tamanho de capítulo, porém a resposta dos genótipos "Paraíso 33", "Hélio 251",
"Hélio 250" e "Hélio 253" foi similar, diferenciando-se apenas do genótipo HLA 211.

No ano agrícola 2008/09, os genótipos não diferiram entre si dentro e entre as épocas para a variável tamanho de capítulo (Tabela 2), porém, para o ano de 2009/10, houve diferença significativa para "Hélio 251", para o qual se verificou redução significativa desta variável da primeira até a terceira época, enquanto que o "Hélio 250" somente reduziu significativamente o tamanho de capítulos na terceira época; não houve diferença entre os anos testados para esta variável.

Em ensaios nacionais conduzidos pela EMBRAPA (2006), o tamanho de capítulo ficou em média de $15,30 \mathrm{~cm}$ de diâmetro, valor próximo ao obtido no presente estudo (Tabela 1). Porém, CASTRO \& FARIAS (2005) enfatizaram que o diâmetro de capítulos está dentro das características quantitativas e morfológicas do girassol e as diferenças se devem a características intrínsecas de cada genótipo e que são grandemente influenciadas pelas diferentes condições ambientais e pelo manejo adotado na cultura, podendo variar de 7 a $40 \mathrm{~cm}$.

\section{CONCLUSÃO}

A altura de planta é influenciada pelas épocas de semeadura e pelo ambiente de cultivo, enquanto que o tamanho do capítulo é influenciado 
somente pelo ambiente. $\mathrm{O}$ rendimento da cultura do girassol é influenciado pelas condições ambientais e pela época de semeadura. $\mathrm{O}$ atraso na época de semeadura determina decréscimo do rendimento de aquênios.

\section{AGRADECIMENTOS}

Ao Conselho Nacional de Desenvolvimento Cientifico e Tecnológico (CNPq), pelo auxílio financeiro e concessão de Bolsa de Produtividade em Pesquisa.

\section{REFERÊNCIAS}

AFFÉRRI, F.S. et al. Avaliação de cultivares de girassol, em diferentes épocas de semeadura, no sul do Estado do Tocantins, safra 2005/ 2006. Amazônia: Ciência \& Desenvolvimento, Belém, v.4, n.7, p.79-87, 2008. Disponível em: <http://www.basa.com.br/ bancoamazonia2/Revista/edicao_07/C\&D_N_VII_Avaliacao_ de_Cultivar.pdf>. Acesso em: 08 fev. 2012.

ALLARD, R.W. Principle of plant breeding. 3.ed. New York: J. Wiley, 1960. 485p.

BACKES, R.L. et al. Desempenho de cultivares de girassol em duas épocas de plantio de safrinha no planalto norte catarinense. Scientia Agraria, Curitiba, v.9, n.1, p.41-48, 2008. Disponível em: <http://www.redalyc.org/redalyc/html/995/99516828007/ 99516828007_5.html>. Acesso em: 08 fev. 2012.

CASTIGLIONI, V.B.R. et al. Fases de desenvolvimento da planta do girassol. Londrina: EMBRAPA-CNPSo, 1994. 24p. (Documentos n.58).

CASTRO, C. et al. A cultura do girassol. Londrina: EMBRAPA-Soja, 1997. 36p. (Circular Técnica, 13).

CASTRO, C.; FARIAS, J.R.B. Ecofisiologia do girassol. In: LEITE, R.M.V.B.C. et al. (Eds.). Girassol no Brasil. Londrina: EMBRAPA-Soja, 2005. Cap.9, p.163-218.

CONAB (Companhia Nacional de Abastecimento). Disponível em: 〈http://www.conab.gov.br/conabweb〉. Acesso em: 05 jul. 2010.

EMBRAPA. Informes da avaliação de genótipos de girassol. 2004/2005 e 2005. Londrina: EMBRAPA Soja, 2006. 118p. (Documento 271). Acesso em: 08 fev. 2012. Online. Disponível em: <http://www.redebiodiesel.com.br/publicacao/6.pdf $>$.

LEITE, R.M.V.B.C. et al. Indicações para o cultivo de girassol nos Estados do Rio Grande do Sul, Paraná, Mato Grosso do Sul, Mato Grosso, Goiás e Roraima. Londrina: EMBRAPA-Soja, 2007. 4p. (Comunicado Técnico, n.78). Acesso em: 08 fev. 2012. Online. Disponível em: <http:// www.cnpso.embrapa.br/download/indicacoes_ girassol_2007.pdf>.
LOPES, P.V.L. et al. Estudos de diferentes espaçamentos na cultura do girassol. In: REUNIÃO NACIONAL DE PESQUISA DO GIRASSOL, 18.; SIMPÓSIO NACIONAL SOBRE A CULTURA DO GIRASSOL, 6., 2009, Pelotas, RS. Anais... Pelotas: EMBRAPA Clima Temperado, 2009. Acesso em: 08 fev. 2012. Online. Disponível em: <http://www.alice.cnptia.embrapa.br/ bitstream/doc/573699/1/29887.pdf>.

MELLO, R. et al. Características fenológicas, produtivas e qualitativas de girassol em diferentes épocas de semeadura para produção de silagem. Revista Brasileira de Zootecnia, Viçosa, v.35, n.3, p.672-682, 2006. Disponível em: <http://www.scielo.br/ pdf/rbz/v35n3/30056.pdf>. Acesso em: 08 fev. 2012.

PIMENTEL-GOMES, F. Curso de estatística experimental. Piracicaba: Nobel, 1990. 476p.

PORTO, W.S. et al. Adaptabilidade e estabilidade como critérios para seleção de genótipos de girassol. Pesquisa Agropecuária Brasileira, Brasília, v.42, n.4, p.491-499, 2007. Disponível em: <http://dx.doi.org/10.1590/S0100-204X2007000400006>. Acesso em: 08 fev. 2012. doi: 10.1590/S0100-204X2007000400006.

RÊGO FILHO, L.M. et al. Avaliação de genótipos de girassol na região Norte do Estado do Rio de Janeiro - Terceira época de semeadura (fevereiro 2006). In: CONGRESSO BRASILEIRO DE PLANTAS OLEAGINOSAS, ÓLEOS, GORDURAS E BIODIESEL, 3., 2006, Varginha, MG. Anais... Varginha: Universidade Federal de Lavras, 2006. 1 CD.

SAS LEARNING EDITION. Programa SAS - Getting started with the SAS Learning Edition. Cary: SAS Publishing, 2002. 200p.

SILVA, A.G. et al. Desempenho de híbridos de girassol em espaçamentos reduzidos. Ciências Agrárias, Londrina, v.30, n.1, p.31-38, 2009. Disponível em: <http://www.uel.br/revistas/ uel/index.php/semagr arias/article/download/2619/2282>. Acesso em: 08 fev. 2012.

SILVA, P.R.F.; MUNDSTOCK, C.M. Estabelecimento da lavoura. In: SILVA.,P.R.F. Girassol: indicações para o cultivo no Rio Grande do Sul. Porto Alegre: UFRGS, Secretaria da Agricultura, Departamento de pesquisa, IPAGRO, 1990. 71p.

SHEAFFER, C.C. et al. Potential of sunflowers for silage in double-cropping systems following small grains. Agronomy Journal, Madison, v.69, n.4, p.543-546, 1977.

UNGARO, M.R.G. et al. Parâmetros fisiológicos, produção de aquênios e fitomassa de girassol em diferentes épocas de cultivo. Bragantia, Campinas, v.59, n.2, p.205-211, 2000. Disponível em: <http://dx.doi.org/10.1590/S0006-87052000000200012〉. Acesso em: 08 fev. 2012. doi; 10.1590/S000687052000000200012 . 